\title{
Knowledge, Attitude and Practice of Dental Students Regarding Denture Adhesives - A Survey Based Analysis
}

\author{
B. John Rozar Raj', Dhanraj Ganapathy ${ }^{2}$ and Subashree. $R^{3}$ \\ ${ }^{1}$ Saveetha Dental College and Hospitals, Saveetha Institute of Medical \\ and Technical Science, Saveetha University, Chennai 77, India \\ ${ }^{2}$ Professor and Head, Department of Prosthodontics, Saveetha Dental College and Hospitals, Saveetha \\ Institute of Medical and Technical Science, Saveetha University, Chennai 77, India \\ ${ }^{3}$ Senior Lecturer, Department of Prosthodontics Saveetha Dental College and Hospitals, Saveetha \\ Institute Of Medical and Technical Science, Saveetha University, Chennai 77, India
}

\section{ABSTRACT}

The aim of the study was to determine the knowledge, attitude and practise of dental students regarding denture adhesives. Denture adhesive improves retention, decreases tissue discomfort, prevents strangulation of mucosal blood supply, and reduces the frequency of adjustments even in a well-fitting denture.Denture wearers sometimes wear denture adhesive to enhance the retention of their prosthesis. Denture adhesive is likely to be favorable and the retention of the denture becomes better with the usage of denture adhesive.This was a questionnaire based study. The study setting was a University setting. A pre-tested questionnaire with 8 questions was formulated for the collection of information. They were distributed to 100 dental students at a private dental institution and their answers were recorded. Excel Tabulation was done. Results were represented in the form of pie charts. In this study, all the dental students were aware of the denture adhesives. 92\% of them have used denture adhesives to improve the retention of the denture. Denture adhesive was more commonly used for complete dentures(88\%). Majority of the students believed that patients felt happy after the usage of denture adhesives. From the present study, we can conclude that the dental students had comparatively better understanding and knowledge about the principles of denture adhesives. But the knowledge about different forms of denture adhesives and awareness about the complications that might arise after long term usage of denture adhesives were very less, so better training and work experience can help them to understand about the advancements and the significance of denture adhesives.

KEY WORDS: ADHESIVES, DENTURES, RETENTION, STABILITY.

\section{ARTICLE INFORMATION}

*Corresponding Author: dhanraj@saveetha.com

Received 27th June 2020 Accepted after revision 10th August 2020

Print ISSN: 0974-6455 Online ISSN: 2321-4007 CODEN: BBRCBA

Thomson Reuters ISI Web of Science Clarivate Analytics USA and Crossref Indexed Journal

\section{Clarivate
Analytics}

NAAS Journal Score 2020 (4.31) SJIF: 2020 (7.728)

A Society of Science and Nature Publication,

Bhopal India 2020. All rights reserved.

Online Contents Available at: http//www.bbrc.in/

Doi: http://dx.doi.org/10.21786/bbrc/13.7/97 


\section{INTRODUCTION}

Denture wearers sometimes wear denture adhesive to enhance the retention of their prosthesis. Denture adhesive is likely to be favorable and the retention of the denture becomes better with the usage of denture adhesive(Kelsey, Lang and Wang, 1997) Denture adhesive improves retention, decreases tissue discomfort, prevents strangulation of mucosal blood supply, and reduces the frequency of adjustments even in a well-fitting denture(Tarbet, Boone and Schmidt, 1980; Shay, 1991).

Adhesives provide a cushioning and lubricating effect that reduces friction and mucosal irritation(Scher, Ritchie and Flowers, 1978) The composition of denture adhesive is such as, the main ingredients of denture adhesives are classified into three groups which are Group 1 (adhesive agents), Group 2 (antimicrobial agents), and Group 3 (other agents)(Boone, 1984; Adisman, 1989).

The viscosity of the adhesive is increased by the thickness of saliva formed, thereby increasing the denture retention. Newer adhesive materials provide stronger bioadhesive and cohesive forces, hereby free carboxyl groups formed by the hydration of adhesive such as methyl cellulose, hydroxymethyl cellulose, sodium carboxymethyl cellulose, or polymethyl vinyl ether maleic anhydride and thus form electrovalent bonds that produce stickiness or bioadhesion(Duqum et al., 2012).

Furthermore, there are few requirements of an ideal denture adhesive which are, it should be biocompatible, non-toxic, and also non-irritant. It should have a neutral odor and also neutral taste with an ease for application and removal from the tissue surface of the denture. The denture adhesiveness should be able to retain for about 12-16 h(Figueiral et al., 2011).

Finally, the denture adhesive should discourage microbial property and increase the comfort, retention, and stability of the denture. The most commonly mode of application of denture adhesive is that any residual adhesive should be removed from the tissue-bearing surface of the denture (Figueiral et al., 2011; Philip, Ganapathy and Ariga, 2012) the use of adhesives in patients with compromised denture- bearing areas adds to their confidence, thereby increasing the ability to adapt to the new prosthesis.

Immediate denture gets loosened soon due to tissue healing and resorption requiring relining, rebasing, or a new denture fabrication, and comfort and function during the interim period are aided by the use of a denture adhesive. Reduced clinical findings of ulcers, tissue irritation, inflammation, and compression of the oral mucosa of denture wearers were seen with concomitant use of adhesives(Panagiotouni et al., 1995).

Xerostomia in denture wearers either drug or radiotherapy induced can be alleviated with the use of denture adhesives and stabilization of dentures in patients with hormonal changes and neuromuscular disorders such as myasthenia gravis, Parkinson's and Alzheimer's disease, and more can be achieved with denture adhesives. Prosthesis to rehabilitate gross maxillofacial defect requires denture adhesives for retention and is valuable adjuncts to the retention of radiation carriers or radiation protection prosthesis(Polyzois, 1983)

The disadvantages in the usage of denture adhesive such as allergies to denture adhesives or any of its components, gross inadequacies in retention and function, excessive bone resorption, and soft tissue shrinkage, leading to loss of vertical dimension, adhesives should not be used to retain fractured dentures or dentures with lost flanges and patients with inability to maintain proper hygiene of the denture should avoid the use of denture adhesive(Roshene, Robin and Raj, 2015; Kumaran, Sharma and Robin, 2019).

Previously our department has published extensive research on various aspects of prosthetic dentistry ('Evaluation of Corrosive Behavior of Four Nickelchromium Alloys in Artificial Saliva by Cyclic Polarization Test:An in vitro Study', 2017; Ganapathy, Kannan and Venugopalan, 2017; Jain, 2017a, 2017b; Ranganathan, Ganapathy and Jain, 2017; Ariga et al., 2018; Gupta, Ariga and Deogade, 2018; Anbu et al., 2019; Ashok and Ganapathy, 2019; Duraisamy et al., 2019; Varghese, Ramesh and Veeraiyan, 2019), this has provided a platform for us to pursue the current study.

The aim and objective of this study was to provide information on the level of awareness among the dental students in Chennai and the current status of knowledge, attitude and practice towards the use of denture adhesives.

\section{MATERIAL AND METHODS}

The study was conducted in a private dental institution in Chennai. The study setting was carried out in a University setting with approval of the Institutional review board.

Inclusion criteria and Exclusion criteria: Undergraduate third year students, final year students and Interns were included in the study. Post graduate students and dental practitioners were excluded from the study.

Data Collection: A pre-tested questionnaire with 8 questions was formulated for the collection of information. The questionnaire was simple and brief. The self made questions were developed. The questionnaire included self made questions to assess about the knowledge, practise and awareness among the dental students regarding denture adhesives. The questionnaire was shared with 100 dental students and their answers were recorded using an online surveying tool( Google Forms). Data was entered in Microsoft Excel sheets. The results were demonstrated in the form of pie charts. 


\section{RESULTS AND DISCUSSION}

The survey gathers the knowledge about denture adhesives among the dental students. This would in turn greatly benefit its use in their clinical practice in providing guidance in use for patients requiring them. Figure 1 showed that all the dental students were aware of the denture adhesives. In the study by Al Taweel.et.al, $97 \%$ of the respondents were aware about the denture adhesives (Al Taweel and Al Shehri, 2016).In the study by Fakhri.et.al, it was showed that 14\%,32\% and 37\% of the general dentists had respectively, good, moderate and weak knowledge towards denture adhesive while 16.3\% had no knowledge about this material (Fakhri et al., 2009). Denture adhesives has not yet gained worldwide dentist acceptance. This may be due to very limited knowledge about denture adhesives among dentists and also the lack of importance given to this topic either in the undergraduate curriculum or in continuing dental education programmes(Lamb, 1980; Özcan et al., 2004; Zhao et al., 2004).

Figure 1 : Pie chart depicts the students response on the awareness of denture adhesives. All the dental students were aware(Blue) of denture adhesives.

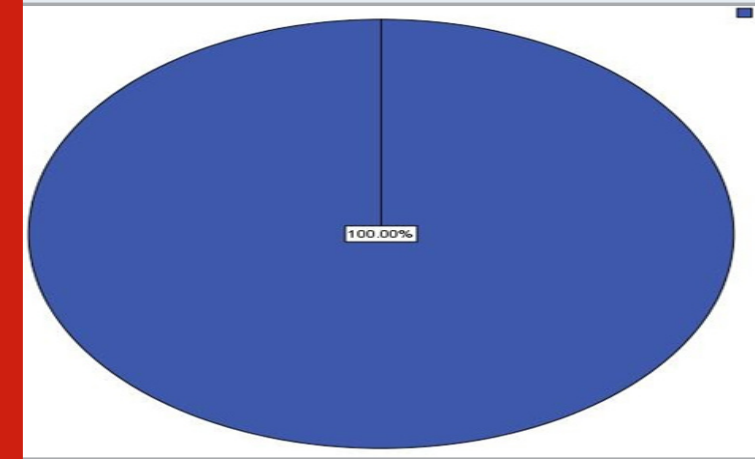

Figure 2: Pie chart depicts the students response to the use of denture adhesives in their clinical practice. 92\% of the students have used(Blue) denture adhesives in their clinical practice while the remaining $8 \%$ of them have never used(Green) denture adhesives.

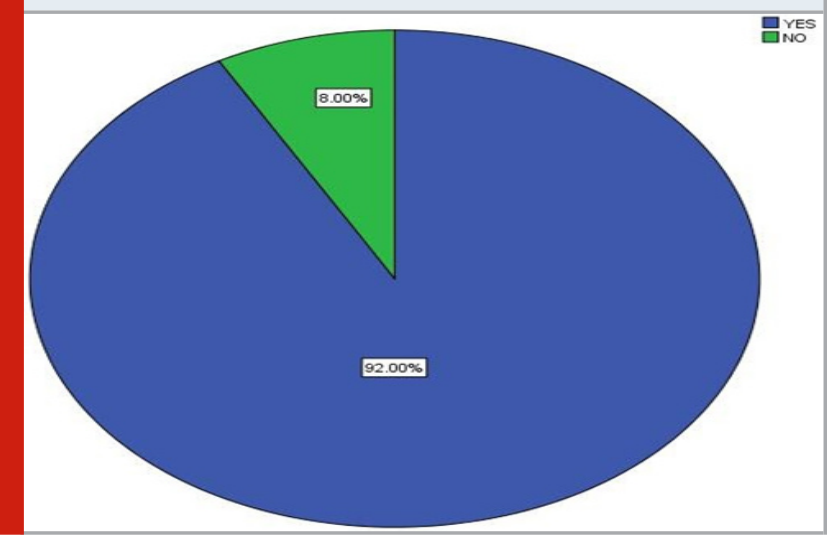

In our study, Figure 2 showed that $92 \%$ of the dental students have used denture adhesives in their clinical practice. In the study by $\mathrm{Al}$ Taweel.et.al, only $52.2 \%$ of the respondents have used denture adhesives in their clinical practise. This was very less when compared to our study. In the study by Mantri.et.al, a total of 115(83\%) general dental practitioners, $6(100 \%)$ prosthodontists and $22(81 \%)$ other specialist's used denture adhesives as a beneficial adjunct in their clinical practice(Mantri et al., 2014). In the study by Muneer.et.al, among a group of 96 dentists in Pakistan, 56\% had never prescribed DAs to any patient and 44\% had no knowledge regarding their use (Muneer, Ahmed and Kamran, 2013)

In our study, Figure 3 showed that out of the 92 patients who have used denture adhesives, $82.6 \%$ of them used denture adhesives mostly for complete dentures while the remaining $17.4 \%$ of them used it for partial dentures. Study by Kulak.et.al, reported that non retentive and unstable mandibular denture was the major problem faced by the complete denture patients(Kulak, Ozcan and Arikan, 2005).

Figure 3: Pie chart depicts the students response on the type of prosthesis in which the denture adhesive was used. Out of the 92 patients who have used denture adhesives in their clinical practice, $82.6 \%$ of them used denture adhesives for complete dentures(Blue) while the remaining $17.4 \%$ of them used it for partial dentures (Green).

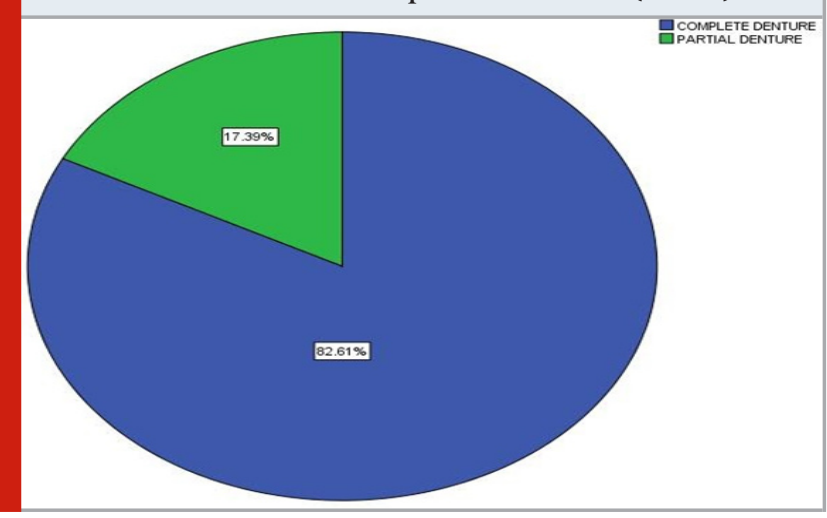

Figure 4: Pie chart depicts the students response to the awareness about different forms of denture adhesives. Only $43 \%$ of the students were aware(Blue) about the different forms of denture adhesives while the remaining 57\% were completely unaware(Green) about it.

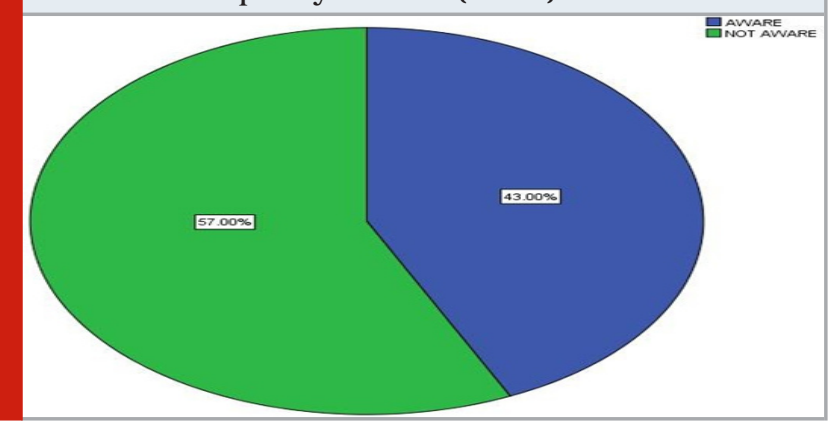

In our study, Figure 4 showed that only $43 \%$ of them were aware about the different forms of denture adhesives. Denture adhesives are available as powders, gels, strips 
and creams.study by El and Habib reported that the use of adhesive creams significantly increased the denture retention. They also reported that it was difficult to remove the paste type denture adhesives from the denture fitting surface by using mouthrinse and/or cotton gauzes (El and Habib, 2012).

In our study, Figure 5 showed that more than half of the participants (62\%) did not feel that the use of denture adhesive was viewed as a poor reflection on their clinical skills. In the study by Fakhri.et.al, only 9.3\% of the dentists had a positive attitude towards using this material(Fakhri et al., 2009). In the study by Al Taweel. et.al, the participants agreed that denture adhesives are useful for stabilizing trial bases during the early stages of denture fabrication(62.3\%), enhancing retention during the interim period(75.4\%), providing additional retention for patients with inadequate oral anatomy(75.4\%) and helping patients to overcome their anxiety after the insertion of a completely new denture(68.1\%)(Al Taweel and Al Shehri, 2016).

Figure 5: Pie chart depicts the students response to the feeling whether the use of denture adhesive is viewed as a poor reflection on their clinical skills. $62 \%$ of them did not feel(Blue) that the use of denture adhesive was viewed as a poor reflection on their clinical skills. $38 \%$ of the students felt less confident(Green) in their clinical skills while using denture adhesives.

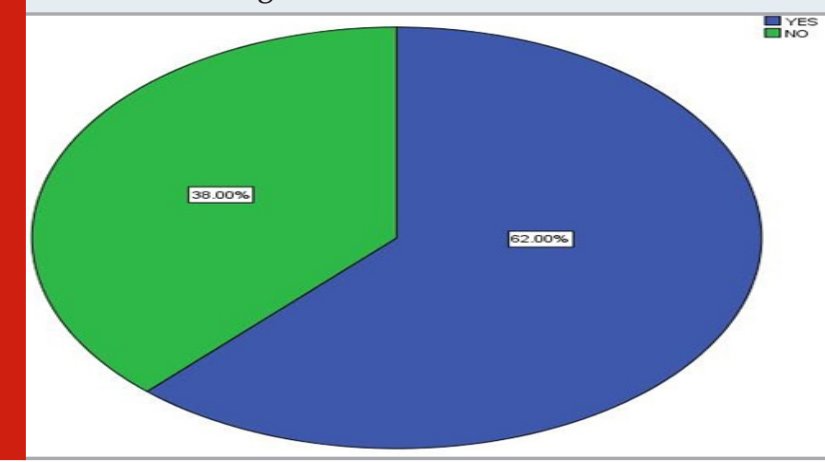

Figure 6: Pie chart depicts the students response to the patient's satisfaction after the usage of denture adhesives. $74 \%$ of the students believed that the patients were very much satisfied(Blue) after using denture adhesives while the remaining $26 \%$ of them felt that the patients were not satisfied(Green) even after using denture adhesives.

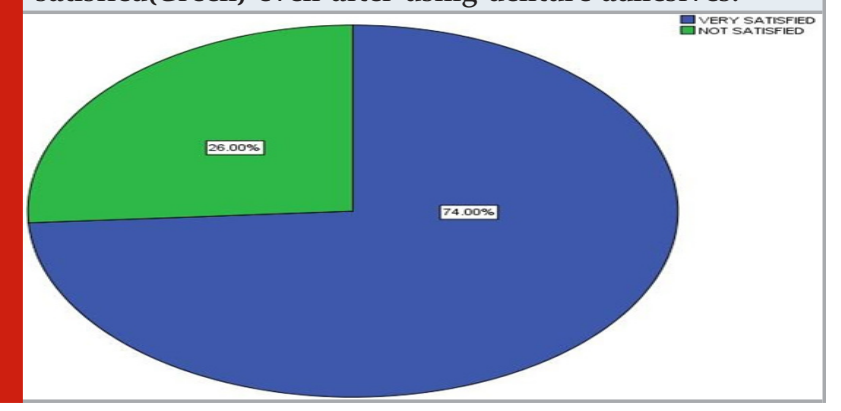

In our study, Figure 6 showed that 74\% of the dental students believed that the patients felt after the usage of denture adhesives. In the study by El and Habib, it was reported that the majority of the patients were either very satisfied or fairly satisfied when they used the denture adhesives in maxillary denture. The satisfactory rate for retention in mandibular dentures was still worse when compared to maxillary dentures(El and Habib, 2012). Neill and Roberts reported that the use of denture adhesives provided satisfactory improvement in mastication performance in subjects with poor and ill fitting dentures(Neill and Roberts, 1973).

In our study, Figure 7 showed that all the participants agreed to the fact that patient education about denture adhesive was very important. In the study by Al Taweel. et.al, participants had a comparatively stronger opinion regarding the patient education on the denture adhesives and believed it to be an important part of denture service(Al Taweel and Al Shehri, 2016). Study by Mantri. et.al stated that dentists need to possess knowledge in order to educate all dentures wearing patients about the material as they are widely used in the removable prosthetic care(Mantri et al., 2014).

Figure 7: Pie chart depicts the students response on the importance of patients' education about denture adhesives. All the dental students felt that it was very important(Blue) to educate the patients about the denture adhesive material.

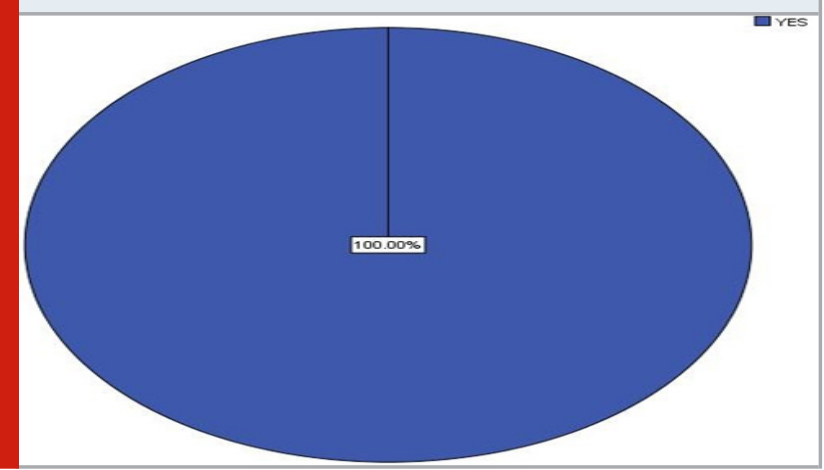

In our study, Figure 8 showed that only 54\% of the dental students were aware about the complications that might arise after long term usage of denture adhesives. In the study by Mantri.et.al, $47 \%$ of the general dental practitioners were ignorant that prolonged use of denture adhesives on ill fitting dentures would result in Residual ridge resorption(Mantri et al., 2014). Stafford.et.al indicated that denture adhesives could influence oral flora by causing an imbalance in the flora(Stafford and Russell, 1971). In the study by $\mathrm{Al}$ Taweel.et.al, majority of the respondents agreed that denture adhesives contribute to the development of denture stomatitis, candidiasis and imbalance in the oral flora(Al Taweel and Al Shehri, 2016). In the study by Fakhri.et.al, 65\% of the dentists agreed that over usage of denture adhesives can cause denture adhesives and an imbalance in oral flora(Fakhri et al., 2009). 
Figure 8: Pie chart depicts the students response to the awareness about the complication that might arise after the long term usage of denture adhesives. Only 54\% of the students were aware(Blue) about the complications of denture adhesives while the remaining 46\% were completely unaware(Gren) about it.

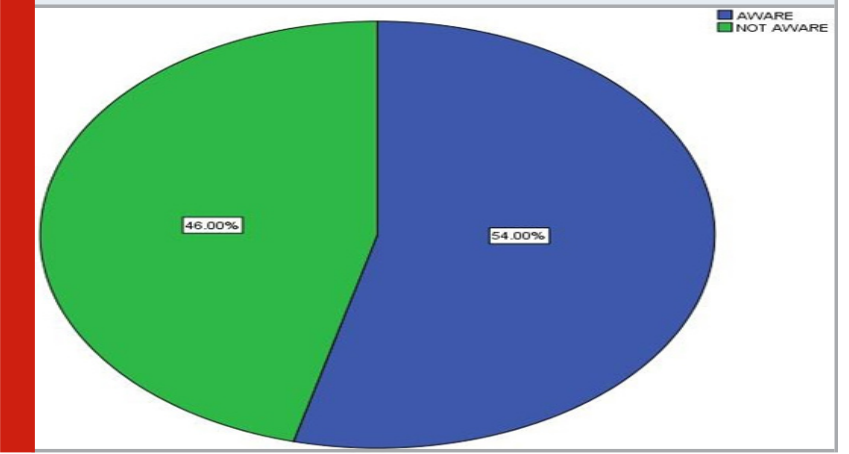

The finding from the present study adds to the consensus of the previous studies. Limitations of the study were smaller sample size so it cannot be generalised to the whole population. Further studies can be done with a larger population.

\section{CONCLUSION}

From the present study, we can conclude that the dental students had comparatively better understanding and knowledge about the principles of denture adhesives. They also gave equal importance to patient's satisfaction and patient education about denture adhesives. But the knowledge about different forms of denture adhesives and awareness about the complications that might arise after long term usage of denture adhesives were very less, so better training and work experience can help them to understand about the advancements and the significance of denture adhesives.

Author Contributions: All the authors have equal contributions in bringing out this research work.

\section{ACKNOWLEDGEMENTS}

The authors are thankful to Saveetha Dental College for providing permission to access the database and for giving a platform to express our knowledge.

Conflicts of Interest: The authors declare no conflicts of interest.

\section{REFERENCES}

Adisman, I. K. (1989) 'The use of denture adhesives as an aid to denture treatment', The Journal of prosthetic dentistry, 62(6), pp. 711-715.

Al Taweel, S. M. and Al Shehri, H. A. (2016) 'Knowledge and attitudes of dental interns toward denture adhesives in King Saud University, Riyadh, Saudi Arabia', European journal of dentistry, 10(4), pp. 536-540.

Anbu, R. T. et al. (2019) 'Comparison of the Efficacy of Three Different Bone Regeneration Materials: An Animal Study', European journal of dentistry, 13(1), pp. 22-28.

Ariga, P. et al. (2018) 'Determination of Correlation of Width of Maxillary Anterior Teeth using Extraoral and Intraoral Factors in Indian Population: A Systematic Review', World Journal of Dentistry, 9(1), pp. 68-75.

Ashok, V. and Ganapathy, D. (2019) 'A geometrical method to classify face forms', Journal of oral biology and craniofacial research, 9(3), pp. 232-235.

Boone, M. (1984) 'Analysis of soluble and insoluble denture adhesives and their relationship to tissue irritation and bone resorption', The Compendium of continuing education in dentistry, Suppl 4, pp. S22-5.

Duqum, I. et al. (2012) 'Denture adhesive use in complete dentures: clinical recommendations and review of the literature', General dentistry, 60(6), pp. 467-77; quiz p. 478-9.

Duraisamy, R. et al. (2019) 'Compatibility of Nonoriginal Abutments With Implants: Evaluation of Microgap at the Implant-Abutment Interface, With Original and Nonoriginal Abutments', Implant dentistry, 28(3), pp. 289-295.

El, N. and Habib, A. (2012) 'Comparison of three different forms of denture adhesives: direCt measurement of denture retention and, study of patient satisfaCtion', Dental journal, 58, p. 1.

Evaluation of Corrosive Behavior of Four Nickelchromium Alloys in Artificial Saliva by Cyclic Polarization Test:An in vitro Study' (2017) World Journal of Dentistry, 8(6), pp. 477-482.

Fakhri, H. et al. (2009) 'The knowledge and attitude of general dentists toward denture adhesives in Tehran', Indian journal of dental research: official publication of Indian Society for Dental Research, 20(2), pp. 164-168.

Figueiral, M. H. et al. (2011) 'The effect of different adhesive materials on retention of maxillary complete dentures', The International journal of prosthodontics, 24(2), pp. 175-177.

Ganapathy, D. M., Kannan, A. and Venugopalan, S. (2017) 'Effect of Coated Surfaces influencing Screw Loosening in Implants: A Systematic Review and Meta-analysis', World Journal of Dentistry, 8(6), pp. 496-502.

Gupta, P., Ariga, P. and Deogade, S. C. (2018) 'Effect of Monopoly-coating Agent on the Surface Roughness of a Tissue Conditioner Subjected to Cleansing and Disinfection: A Contact Profilometric Study', Contemporary clinical dentistry, 9(Suppl 1), pp. S122S126.

Jain, A. R. (2017a) 'Clinical and Functional Outcomes of Implant Prostheses in Fibula Free Flaps', World Journal of Dentistry, 8(3), pp. 171-176.

Jain, A. R. (2017b) 'Prevalence of Partial Edentulousness and Treatment needs in Rural Population of South 
India', World Journal of Dentistry, 8(3), pp. 213-217. Kelsey, C. C., Lang, B. R. and Wang, R. F. (1997) 'Examining patients' responses about the effectiveness of five denture adhesive pastes', Journal of the American Dental Association , 128(11), pp. 1532-1538.

Kulak, Y., Ozcan, M. and Arikan, A. (2005) 'Subjective Assessment by Patients of the Efficiency of Two Denture Adhesive Pastes', Journal of prosthodontics: official journal of the American College of Prosthodontists, 14(4), pp. 248-252.

Kumaran, G. V., Sharma, S. and Robin, K. (2019) 'Usage of denture adhesive in complete denture wearers-A questionnaire-based study', Drug Invention Today, 12(11).

Lamb, D. J. (1980) 'Denture adhesives: a side effect', Journal of dentistry, 8(1), pp. 35-42.

Mantri, S. et al. (2014) 'Knowledge, Attitude and Practices of Denture Adhesives Use Among Private Dental Practitioners' of Jabalpur City, Madhya Pradesh: A Cross Sectional Survey', Journal of Indian Prosthodontic Society. Springer, 14(3), pp. 243-250.

Muneer, M. U., Ahmed, A. R. and Kamran, M. F. (2013) 'AWARENESS OF DENTISTS AND COMPLETE DENTURE WEARERS TOWARDS DENTURE ADHESIVES', Pakistan Oral \& Dental Journal, 33(1).

Neill, D. J. and Roberts, B. J. (1973) 'The effect of denture fixatives on masticatory performance in complete denture patients', Journal of dentistry, 1(5), pp. 219-222.

Özcan, M. et al. (2004) 'The attitude of complete denture wearers towards denture adhesives in Istanbul', Journal of oral rehabilitation. Wiley Online Library, 31(2), pp. 131-134.

Panagiotouni, E. et al. (1995) 'Retentive ability of various denture adhesive materials: an in vitro study', The Journal of prosthetic dentistry, 73(6), pp. 578585.

Philip, J., Ganapathy, D. and Ariga, P. (2012) 'Comparative evaluation of tensile bond strength of a polyvinyl acetate-based resilient liner following various denture base surface pre-treatment methods and immersion in artificial salivary medium: An in vitro study', Contemporary Clinical Dentistry, p. 298. doi: 10.4103/0976-237x.103622.

Polyzois, G. L. (1983) 'An update on denture fixatives', Dental update, 10(9), pp. 579-80, 582-3.

Ranganathan, H., Ganapathy, D. M. and Jain, A. R. (2017) 'Cervical and Incisal Marginal Discrepancy in Ceramic Laminate Veneering Materials: A SEM Analysis', Contemporary clinical dentistry, 8(2), pp. 272-278.

Roshene, R., Robin, P. and Raj, J. D. (2015) 'A survey of denture hygiene in older patients', Research journal of pharmaceutical, biological and chemical sciences. Journal of Pharmaceutical Sciences and Research, 7(10), p. 897.

Scher, E. A., Ritchie, G. M. and Flowers, D. J. (1978) 'Antimycotic denture adhesive in treatment of denture stomatitis', The Journal of prosthetic dentistry, 40(6), pp. 622-627.

Shay, K. (1991) 'Denture adhesives. Choosing the right powders and pastes', Journal of the American Dental Association , 122(1), pp. 70-76.

Stafford, G. D. and Russell, C. (1971) 'Efficiency of Denture Adhesives and their Possible Influence on Oral Microorganisms', Journal of dental research. SAGE Publications Inc, 50(4), pp. 832-836.

Tarbet, W. J., Boone, M. and Schmidt, N. F. (1980) 'Effect of a denture adhesive on complete denture dislodgement during mastication', The Journal of prosthetic dentistry, 44(4), pp. 374-378.

Varghese, S. S., Ramesh, A. and Veeraiyan, D. N. (2019) 'Blended Module-Based Teaching in Biostatistics and Research Methodology: A Retrospective Study with Postgraduate Dental Students', Journal of dental education, 83(4), pp. 445-450.

Zhao, K. et al. (2004) 'Laboratory evaluation of a new denture adhesive', Dental materials: official publication of the Academy of Dental Materials, 20(5), pp. 419424. 